\title{
SAÚDE E CONDIÇÕES DE TRABALHO NAS ORGANIZAÇÕES
}

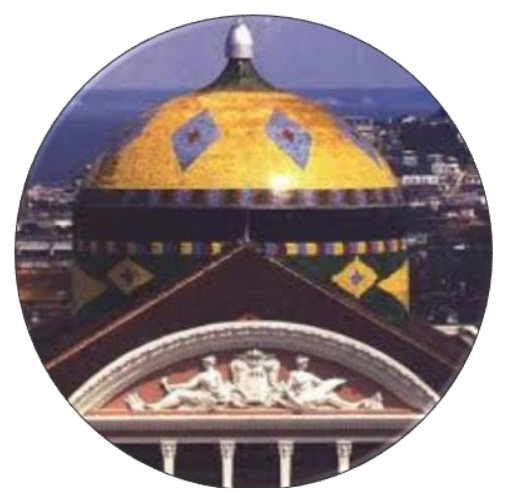

\author{
Aline Maria Osório Freitas ${ }^{1}$ \\ Marcela Seixas Ferreira de Castro ${ }^{2}$
}

\section{Resumo}

O tema a ser estudado neste artigo consiste em conhecer as condições de trabalho nas organizações que interferem na saúde do funcionário, e como trazem conseqüências para o seu bem-estar. A luta pela sobrevivência leva a uma jornada excessiva de trabalho, e as condições em que este se realiza repercutem diretamente na fisiologia do corpo. Serão demonstradas várias doenças decorrentes do ambiente ocupacional, sendo uma delas o estresse, e como os movimentos repetitivos, acidentes, ruído, horário e violência causam prejuízos para a saúde. Através desta pesquisa bibliográfica com abordagem qualitativa e descritiva, espera-se adquirir maiores conhecimentos sobre a saúde do trabalhador e poder contribuir com melhorias para eles.

Palavras-chave: Condições de trabalho.Saúde. Pessoas.

\begin{abstract}
The topic to be studied in this article is to know the working conditions in organizations that interfere with the employee's health, and how they bring consequences for their well-being. The struggle for survival leads to an overworked journey, and the conditions under which it takes place have a direct impact on the physiology of the body. Several diseases arising from the occupational environment will be demonstrated, one of them being stress, and because repetitive movements, accidents, noise, time and violence cause health damage. Through this bibliographical research with a qualitative and descriptive approach, it is expected to acquire greater knowledge about the health of the worker and to be able to contribute with improvements for them.
\end{abstract}

Keywords: Work conditions. Health. People.

\footnotetext{
1 aline.m.osorio@bol.com.br

2 marcela.seixas@gmail.com
} 


\section{Introdução}

O ambiente de trabalho contribui de várias maneiras para a saúde física e o bem-estar emocional dos funcionários. As condições físicas do trabalho tendem a ter efeitos diretos nas pessoas. Algumas vezes, esses efeitos são imediatos, mas frequentemente ocorrem após um longo período de tempo.

A exposição a doenças infecciosas e ao ruído alto pode gerar enfermidades; movimentos repetitivos podem resultar em lesões em várias partes do corpo; acidentes provocam a perda permanente, temporária ou parcial da capacidade para o trabalho; a violência coloca em risco a integridade física, mental e moral do trabalhador; o revezamento de turno perturba a vida familiar e doméstica dos trabalhadores, além de alterar seus ritmos biológicos; e o estresse ocupacional representa ameaça séria para a saúde.

Enfermidades e ferimentos podem ter conseqüências prejudiciais ao bem-estar emocional. Doenças graves e lesões estão quase sempre associadas com algum tipo de angústia e trauma psicológico, principalmente quando a pessoa ficou incapacitada.

Uma fonte de estresse ocupacional é a sobrecarga de trabalho. As pessoas que trabalham em muitas tarefas sentem-se mais estressadas. Outro fator é o conflito de papéis, que é o grau de incerteza dos funcionários sobre suas funções e responsabilidades no trabalho, e reduz seu aproveitamento de todas as tarefas e piora o humor.

O esgotamento profissional ou Burnout é definido como estado de exaustão física e psicológica relacionada com o trabalho que pode ocorrer entre indivíduos que trabalham de alguma forma com outras pessoas. Envolve condutas negativas, sendo uma experiência que acarreta prejuízos práticos e emocionais para o trabalhador e a organização, interfere na vida do indivíduo e na sua relação com o trabalho. O 
esgotamento é mais comum em empregados cujo envolvimento a longo prazo em locais de trabalho frustrantes leva à perda gradual de propósito.

Vemos então que a qualidade de vida torna-se estratégica para a sobrevivência e desenvolvimento futuros das organizações. A idéia de trabalho saudável reconhece que muitos passos podem ser dados para melhorar a saúde dos funcionários e também do seu ambiente de trabalho.

\section{Saúde e condições de trabalho nas organizações}

O Ambiente de trabalho contribui de várias maneiras para a saúde física e o bem-estar emocional dos funcionários. O impacto do ambiente de trabalho é direto e imediato: um funcionário pode ferir-se ou morrer no trabalho e pode também ser indireto, pois pode levar anos até que uma lesão ocorra. Certas condições que não são físicas, também podem afetar a saúde e o bem-estar emocional como o estresse no trabalho.

Um ambiente de trabalho seguro e saudável protege os trabalhadores de ameaças à sua saúde e ao mesmo tempo amplia a capacidade para o trabalho e a produtividade.

De acordo com Dejours (2010) quando o rearranjo da organização do trabalho não é possível,quando a relação do trabalhador com a organização é bloqueada,o sofrimento começa ocasionando um sentimento de desprazer e tensão.

\subsection{Doenças}

Segundo Guimarães "Doença dize-se de qualquer afastamento do quadro normal de saúde” (2002, p.162).

Conforme Spector (2005), os profissionais que lidam como público (por exemplo, cabeleireiros, policiais,vendedores ou professores) podem ser expostos a doenças infecciosas, apesar de a maioria dos casos 
resultar em doenças pouco sérias, como a gripe.A exposição a doenças infecciosas é particularmente preocupante para profissionais da saúde, que lidam com pacientes muito doentes ou em risco de vida.

Para o mesmo autor, em muitas ocupações os funcionários podem ser expostos a substâncias tóxicas. Os trabalhadores de indústrias químicas ou dedetizadores e trabalhadores em fazendas que utilizam inseticidas podem esperar ser expostos. Pessoas que trabalham em escritórios localizados em prédios fechados podem ser expostos a vários produtos químicos, como toners de máquinas copiadoras ou solventes utilizados para a limpeza de tinta. As reações a esta exposição podem variar de sintomas menos graves, como dores de cabeça ou náuseas, até condições sérias, que podem danificar órgãos vitais como os rins ou o fígado.

Além disso, enfermidades e ferimentos podem ter conseqüências psicológicas prejudiciais ao bem-estar emocional. Doenças graves e lesões estão quase sempre associadas com algum tipo de angústia e trauma psicológico, principalmente quando a pessoa ficou incapacitada.

A maioria dos profissionais de saúde teme ser contaminada pelo vírus da Aids por intermédio de seus pacientes.A exposição à Aids é uma das principais fontes de estresse no trabalho, frequentemente levando à ansiedade e à angústia.

Os profissionais de saúde que lidam com a morte, necessitam de apoio diante de situações de luto em suas profissões. Eles também experimentam reações desagradáveis. De acordo com Stedeford (1986), tanto faz aceitar a morte de um paciente terminal ou reprimi-la, isso provoca tensão, fadiga, atividade exagerada, irritabilidade e outros problemas no profissional e até prejudica a eficiência no trabalho e interfere na vida pessoal e familiar.

Nós, profissionais da saúde, nos nossos cursos, não discutimos sobre a morte. A gente discute a cura e, de repente, diante de uma doença terminal, quando se 
veem pessoas jovens que acham que não têm um futuro,a gente vai encarar a nossa própria morte.Por outro lado,há a questão do trabalho, que condições de trabalho nós temos? Que qualidade de saúde existe no Brasil? Que política de saúde? (PAIVA,1992, p:39).

As condições de trabalho não permitem aos profissionais elaborarem o luto, pois este surge das relações estabelecidas com o paciente terminal. $\mathrm{Na}$ vida de um profissional de saúde, muitos não possuem espaço físico ou tempo para elaboração das perdas. Os profissionais de saúde não possuem boa qualidade de trabalho no Brasil.

\subsection{Movimentos repetitivos}

Muitos empregos exigem a repetição física de movimentos de várias partes do corpo. Segundo Spector (2005), movimentos repetitivos podem resultar em lesões por esforço repetitivo (LER), em que partes do corpo ficam inflamadas e, às vezes, permanentemente danificadas. Acontece com funcionários que utilizam computadores no trabalho e também naqueles que trabalham em linhas de produção. Uma combinação entre o projeto de equipamento adequado e paradas para descanso pode ser útil para reduzir a probabilidade do surgimento dessas lesões.

Para Araújo (2011), trata-se de um desgaste em determinada parte do corpo, envolvendo lesões musculares e desgaste nas articulações e nervos, causando dores e inflamações. A lesão é causada pela repetição de um mesmo movimento durante um longo período de tempo. As profissões mais atacadas são as em que é necessário o uso do computador como também em outros profissionais: costureiras, motoristas, pianistas, etc.

Apesar de os casos leves serem aliviados por meio do repouso, os mais graves podem resultar em danos permanentes. As cirurgias, às vezes, podem reparar a lesão, mas nem sempre. 


\subsection{Acidentes no trabalho}

Para Chiavenato podemos conceituar acidente do trabalho "como decorrente do trabalho provocando direta ou indiretamente, lesão corporal, perturbação funcional ou doença que determine a morte, a perda total ou parcial permanente ou temporária da capacidade para o trabalho" (2002, p.440)

A prevenção de acidentes tem sido uma das principais preocupações das organizações, devido aos custos gerados pelos acidentes, tanto para o funcionário como para a empresa.

De Acordo com Enciclopédia:

O acidente de trabalho é definido pela legislação brasileira como toda redução ou perda de capacidade laborativa que seja causada por fatores exógenos e traumáticos relacionados ao trabalho. Deve haver dois critérios: etiologia laboral e lesividade. Não se considera acidente de trabalho um dano sem repercussão na capacidade laborativa ou que tenha origem fora do trabalho (2012, p.2)

Uma importante dificuldade na prevenção dos acidentes no local de trabalho é a obtenção da cooperação dos funcionários na utilização do equipamento de segurança adequado e na adoção de comportamentos seguros. Determinadas práticas são vistas como perda de tempo, ou envolvem muito esforço, ou ainda demonstram falta de coragem de seu usuário para enfrentar situações perigosas.

\subsection{Ruído}

O ruído excessivo está presente em muitos trabalhos, particularmente naqueles que envolvem maquinaria e equipamentos pesados. Aeroportos, construções, fábricas e minas são lugares barulhentos, 
expondo os funcionários a condições que podem afetar sua saúde e seu desempenho no trabalho.

Para Mendes:

O ruído e as conseqüentes perdas auditivas relacionadas ao trabalho ao afetarem a comunicação, prejudicam relacionamentos interpessoais, desempenhos e a própria proteção ante riscos de acidentes. Resultam em perda de autoestima, insegurança e frustrações que convergem para que se estabeleça isolamento social que pode se acompanhar de quadros depressivos (2005, $\mathrm{p}: 1143)$.

De acordo com Chiavenato (2002) o ruído é considerado um som ou barulho indesejável. A sua exposição prolongada produz perda de audição e seu efeito desagradável depende da intensidade do som, sua variação dos ritmos e frequência.

A exposição ao ruído excessivo, como explosões, pode danificar gravemente a audição de uma pessoa, às vezes de forma permanente. Ruídos dessa magnitude são dolorosos, e a maioria das pessoas evita os locais onde estes sons ocorrem. O ruído interfere na maior concentração exigida pelos trabalhos complexos, servindo assim como um fator de estresse no trabalho.

\subsection{Horário de trabalho}

Trabalho em turnos, utilizado para permitir a continuidade do trabalho na empresa além da carga diária de cada trabalhador, assim como trabalho noturno ou em horários irregulares são prejudiciais à saúde dos trabalhadores

Mendes (2005) afirma que o envelhecimento pode ser acelerado pelo trabalho prolongado em situações penosas. Segundo análises, alguém cuja vida laboral decorreu no regime de turnos alternados envelheceu sete anos suplementares. 
De acordo com Straub (2005) o trabalho em revezamento de turno envolve a mudança da equipe de trabalho, com grupos que trabalham em horários diferentes. Os turneiros enfrentam perturbações na vida familiar e doméstica, além de alterar seus ritmos biológicos. O trabalho em revezamento dessincroniza os ritmos e pode levar a inúmeras queixas relacionadas com saúde, problemas gastrintestinais e doenças cardíacas.

\subsection{Violência no trabalho}

Para Zanelli (2004), bem-estar e saúde poderiam ser aspectos psíquicos, mentais e/ou emocionais dos trabalhadores, a partir de taxas epidemiológicas de distúrbios e/ou doenças mentais. Sob análise social, para a violência no trabalho, podem ser fatores as condições de trabalho com estresse e também que tragam perigos ou riscos para a integridade física, mental e moral do trabalhador. A ausência de tais fatores ameaçadores no ambiente de trabalho contribui para promover, como também proteger, tanto o bem-estar quanto a saúde do trabalhador.

Com relação à violência no trabalho, para Spector (2005) ataques fatais podem ser um risco comum, para os que trabalham com o público. Pessoas que trabalham em casas de saúde, órgãos de assistência social e hospitais correm o maior risco de ataques. Os funcionários responsáveis pela leitura de mediadores de água ou luz, instaladores de telefones e vendedores de porta em porta podem ter problemas com cães. Veterinários, tratadores do zoológico e trabalhadores em fazendas podem ser feridos por animais.

Os ataques a funcionários podem ser praticados por pessoas ou animais. Muitas instituições de saúde sedam pacientes agressivos. Várias instituições oferecem também treinamento especializado para ajudar os funcionários a evitar ataques e se defender de pacientes. 


\subsection{Estresse Ocupacional}

Muitos estudos sobre estresse têm sido realizados para identificar quais condições e características do trabalho produzem esse estado. Eles definem o estresse envolvendo sempre um estímulo externo; respostas psicológicas frente àquele estímulo e conseqüências, nas quais o bem-estar do indivíduo está envolvido.

Apesar de as conseqüências a longo prazo do estresse para a saúde humana ainda não estarem claras, a maioria dos pesquisadores do assunto acredita que condições ou trabalho desfavoráveis podem afetar a saúde e o bem-estar dos funcionários.O desgaste no trabalho é uma provável reação negativa do funcionário a um fator estressante, como ansiedade, frustração ou sintomas físicos, como dores de cabeça.

Para Zanelli (2004) da mesma forma que a monotonia e a fragmentação de atividades, outros aspectos como sobrecarga, conflito e ambigüidade de papel, também são apontados como possíveis estressores no trabalho.

Sobre um dos fatores do estresse:

A ambiguidade de papéis ocorre quando os trabalhadores não têm certeza do seu trabalho ou dos padrões utilizados para avaliar o seu desempenho. $\mathrm{O}$ conflito de papéis ocorre quando um trabalhador recebe mensagens confusas sobre essas questões de diferentes supervisores ou de colegas de trabalho (Straub, 2005, p.136).

A ambiguidade do papel é o grau de incerteza dos funcionários sobre suas funções e responsabilidades no trabalho. Muitos superiores falham ao não fornecerem diretrizes e rumos claros a seus subordinados, levando à incerteza sobre o que o funcionário deve fazer.

Segundo Straub (2005), o estresse no trabalho às vezes ocorre quando as pessoas tentam equilibrar vários trabalhos diferentes ao mesmo tempo e experimentam a sobrecarga de papéis. Em um estudo realizado, a 
sobrecarga de papéis, associada ao fato de lidar com uma carga pesada de responsabilidades no trabalho e no lar, reduzia o aproveitamento de todas as tarefas e piorava o humor entre mães trabalhadoras.

Vários fatores contribuem para o surgimento de conflitos trabalho-família. No lado da organização, a necessidade de trabalhar muitas horas e a falta de uma flexibilidade de horário pode levar ao conflito. Indivíduos com elevada afetividade negativa notam mais conflito trabalhofamília.

Para Araújo (2004) de acordo com estudos relativos à organização do trabalho, tais como a divisão do trabalho, o conteúdo das tarefas, o ritmo do trabalho, as relações de poder e de responsabilidade, são fontes de tensão que provocam o desgaste por diferentes aspectos: fadiga, depressão, distúrbios psicossomáticos, síndromes neuróticas, alcoolismo, etc.

Se relacionar bem com outras pessoas é um elemento importante do bem-estar. As pessoas que trabalham passam tanto tempo no trabalho, as relações sociais com colegas podem ser das mais importantes. O conflito interpessoal e relações insatisfatórias com os demais podem resultar em diversas tensões.

Sobre o Burnout ou "esgotamento profissional":

A Síndrome de Esgotamento Profissional é composta por três elementos centrais: exaustão emocional (sentimentos de desgaste emocional e esvaziamento afetivo); despersonalização (reação negativa, insensibilidade ou afastamento excessivo do público que deveria receber os serviços ou cuidados do paciente); diminuição do envolvimento pessoal no trabalho (MASLACH apud ARAÚJO, 2001, p.75).

A síndrome de Burnout envolve atitudes e condutas negativas, sendo uma experiência que acarreta prejuízos práticos e emocionais para o trabalhador e a organização. O quadro tradicional de estresse não envolve tais atitudes e condutas, sendo um esgotamento pessoal, que interfere na vida do indivíduo, mas não de modo direto, na sua relação com o trabalho. 
Os fatores no trabalho para a síndrome mais importantes são: papel conflitante, perda de controle ou autonomia, ausência de suporte social,situação de sobrecarga ou de frustração no trabalho.

Para Aguiar (2005) grande porcentagem de casos encontrados nas organizações é de problemas emocionais que tinham como fatores: restrita ou nenhuma liberdade na execução da tarefa; discussão de idéias ou apresentação de alternativas de ação consideradas contestação da autoridade da chefia, uso de punições, cancelamento salarial e demissões.

De acordo com Dejours (2010) o trabalho torna-se perigoso para o aparelho psíquico quando ele se opõe à sua livre atividade; a energia psíquica se acumula, tornando-se fonte de tensão e desprazer, a carga psíquica cresce até que aparecem a fadiga, a astenia e a partir daí a patologia: é o trabalho fatigante.

A estafa é um estado psicológico que envolve a fadiga e falta de motivação para o trabalho. As pesquisas sobre a estafa descobriram que ela está associada com muitos fatores estressantes do trabalho e desgastes, além de ser considerado um desgaste psicológico.

Segundo Dejours (1992) a alienação ocorre quando o trabalhador se vence pela vontade contida na organização do trabalho a acaba por usar todos os seus esforços para tolerar esse enxerto contra a sua natureza, instalando-se a fadiga.

Os empregos que envolvem responsabilidade com outras pessoas, em vez de responsabilidade com produtos, parecem causar níveis elevados de esgotamento. Este é mais comum entre empregados cujo envolvimento a longo prazo em locais de trabalho muito frustrantes e emocionalmente exigentes leva à perda gradual de propósito e ambição.

De acordo com Straub "o esgotamento é um síndrome multidimensional caracterizada por exaustão emocional, despersonalização e redução em realizações pessoais" (2005, p.135). 
A exaustão emocional refere-se a sentimentos de ter seus recursos emocionais drenados, com perda de energia e sentimentos de fadiga. A despersonalização refere-se à perda de idealismo no local de trabalho, desencadeando atitudes negativas para com aqueles que recebem o serviço ou a atenção do empregado. A redução em realizações pessoais refere-se à perda de sentimentos de competência e realização no trabalho.

Segundo Straub (2005) A redução no número de empregados, as demissões podem ter impacto sério sobre o bem-estar do trabalhador, colocando trabalhadores desempregados em risco de doenças físicas, ansiedade, depressão e até mesmo suicídio. Outros estudos relataram maior consumo de tabaco, álcool e drogas, obesidade e internações hospitalares entre os trabalhadores demitidos.

Secretárias, garçonetes, operários e gerentes intermediários estão entre as ocupações mais estressantes, marcadas por tarefas repetitivas e pouco controle sobre os eventos. Pontos comuns a essas ocupações são queixas de exigências demais, com pouca autoridade para influenciar as práticas de trabalho. O senso de impotência que resulta cria um estresse avassalador (MILLER e SMITH apud STRAUB, 2005, p.136)

A sobrecarga de trabalho interfere no estresse. As pessoas que trabalham muito em muitas tarefas sentem-se mais estressadas, apresentam piores hábitos de saúde, experimentam mais acidentes e sofrem de mais problemas de saúde do que os outros trabalhadores.

\section{Metodologia}

O presente estudo é uma pesquisa bibliográfica com abordagem qualitativa e descritiva.

Para Gil (2002) a pesquisa bibliográfica corresponde àquela que é desenvolvida com base em material já elaborado, constituído de livros e 
artigos científicos tendo como principal vantagem o fato de permitir ao investigador a cobertura de muitos fenômenos mais ampla do que aquela que poderia pesquisar diretamente.

De acordo com Oliveira (2002) a pesquisa descritiva permite a explicação das relações de causa e efeito dos fenômenos, pois o pesquisador necessita obter melhor entendimento a respeito do comportamento de vários fatores e elementos que influem sobre estes fenômenos.

Para o mesmo autor, as pesquisas qualitativas descrevem a complexidade de uma determinada hipótese ou problema, analisam a interação de certas variáveis, compreendem e classificam processos dinâmicos experimentados por grupos sociais, apresentam contribuições no processo de mudança e a interpretação das particularidades dos comportamentos ou atitudes dos indivíduos.

\section{CONSIDERAÇÕES FINAIS}

As condições de trabalho interferem na saúde do trabalhador e trazem conseqüências para o seu bem-estar físico e emocional.

Muitos funcionários ficam expostos a doenças infecciosas e a substâncias tóxicas, o que sempre se associam com angústia e trauma psicológico. Movimentos repetitivos podem resultar em lesões, em que partes do corpo ficam inflamadas e às vezes permanentemente danificadas. Acidentes causam morte, perda total ou parcial da capacidade para o trabalho.

O ruído interfere na concentração para o trabalho, sendo um fator de estresse, além de causar perdas auditivas. Trabalhos em horários irregulares alteram os ritmos biológicos dos funcionários sendo prejudiciais à sua saúde. 
A violência gera perigos ou riscos para a integridade física, mental e moral do trabalhador. O estresse é causado por características do trabalho que produzem esse estado, tais como sobrecarga, conflitos pessoais, ambigüidade de papéis e frustrações.

Assim, este trabalho foi válido para um maior conhecimento de reações e conseqüências experimentadas pelos funcionários em decorrência do ambiente de trabalho para que possamos promover melhorias para estes indivíduos.

É necessário intervir na qualidade de vida no trabalho, através de ações da organização no sentido de implantar inovações gerenciais, tecnológicas e estruturais para preservar a integridade física, psicológica e social do ser humano. É importante uma visão democrática com um aumento da participação dos empregados na tomada de decisões para o alcance de condições de trabalho mais humanas e saudáveis, a fim de criar uma situação favorável à satisfação dos empregados e à produtividade.

\section{Referências}

AGUIAR, Maria Aparecida Ferreira de. Psicologia aplicada à administração: uma abordagem interdisciplinar. São Paulo: Saraiva, 2005.

ARAÚJO, A. Ana Paula de. Lesão por esforço repetitivo. Disponível em: http://cliquesaude.com.br/ler-lesao-por-esforco-repetitivo-204.html.

Acesso em 24nov. 2011

ARAÚJO, Anísio. et al. Cenários do trabalho: subjetividade,movimento e enigma. Rio de Janeiro: DP\&A, 2004.

CHIAVENATO, Idalberto. Recursos Humanos. 7ed. São Paulo: Atlas, 2002.

DEJOURS, Christophe. A loucura do trabalho: estudo de psicopatologia do trabalho. 5ed. São Paulo: Cortez - Oboré,1992. 
- Psicodinâmica do trabalho: contribuições da escola

Dejouriana à análise da relação prazer, sofrimento e trabalho. São Paulo: Atlas, 2010.

GUIMARÃES, Deocleciano Torrieri. Dicionário de termos médicos e de enfermagem. São Paulo: Rideel, 2002.

ENCICLOPÉDIA, Wikipédia. Acidente de trabalho. Disponível em: http://pt.wikipedia.org/wiki/Acidente de trabalho. Acesso em 31 maio 2012

FURASTÉ, Pedro Augusto. Normas Técnicas para o Trabalho Científico: Explicitação das Normas da ABNT. 15.ed. Porto Alegre: s.n., 2010.

GIL, Antônio Carlos. Como elaborar projetos de pesquisa. 3ed. São Paulo: Atlas, 2002

MENDES, Rene. Patologia do trabalho. 2ed. São Paulo: Editora Atheneu, 2005.

OLIVEIRA, Silvio Luiz. Tratado de Metodologia Cientifica: Projetos de Pesquisas, TGI, TCC, Monografias, Dissertações e Teses. São Paulo: Pioneira Thomson Learning, 2002.

PAIVA,Versas. Em tempos de AIDS; viva a vida: sexo seguro, prevenção, drogas, adolescentes, mulheres apoio psicológico aos portadores. São Paulo: Summus,1992

SPECTOR, Paul E. Psicologia nas organizações. São Paulo: Saraiva, 2005

STEDEFORD, Averil. Encarando a morte - Uma abordagem do relacionamento com o paciente terminal. Porto Alegre: Artes Médicas, 1986.

STRAUB, Richard O. Psicologia da Saúde. Porto Alegre: Artmed, 2005

ZANELLI, José Carlos; ANDRADE, Jairo Eduardo Borges; BASTOS, Antonio Virgílio Bittencourt. Psicologia, organizações e trabalho no Brasil. Porto Alegre: Artmed, 2004. 